\title{
Personnel Identification and Management System based on Distributed Computer Network Technology
}

\author{
Xiaorong Zhang \\ Information and Modern Educational Technology Center, Xi'an University,710065
}

\begin{abstract}
Keywords: Distributed Computer Network Technology; Personnel Identification and Management System; Database Management
\end{abstract}

\begin{abstract}
The development of network technology has also driven the application of computer network technology in the personnel identification and management system of enterprises and public institutions. In enterprises and public institutions, there is more and more work on the amount of personnel information and types of personnel information on human resources, which is also becoming more and more complicated. Therefore, traditional manual statistics and processing methods cannot meet the needs of personnel identification and management systems. Therefore, the related database problems of distributed computer network technology for personnel identification and management systems have attracted more and more attention from experts and scholars who are conducting increasing research in this field. In order to improve the efficiency of personnel and management systems in enterprises and public institutions, many enterprises use distributed computer network technology in the personnel identification and management system to manage the integration of personnel information database to improve the efficiency of this work. Therefore, based on the distributed computer network technology, this paper explores the constructive role of enterprise personnel identification and management system.
\end{abstract}

\section{The Influence of Distributed Computer Network Technology in Personnel Identification and Management System}

Efficient personnel identification and system management can make companies more cohesive and dynamic and improve their competitiveness in the market. With the popularity of Internet technology, the organizational structure of enterprises and institutions has also shown a trend of diversification and networking. In order to meet the requirements of this distributed computing network technology, the enterprise personnel identification and management information system also needs to perform audit optimization through a distributed database system. The personnel identification and management system based on distributed computer network technology is a management system with rapid development and high degree of technical professionalism. Therefore, it is of great significance to the research and development of distributed database management system in technical aspects.

Distributed computer network technology has high security and fast maintenance. Distributed computer network technology mainly refines a large computer network system into $\mathrm{N}$ peer networks with corresponding MIBs and responsible for their respective management information and data. It can perform balanced data processing; it can share and exchange information between computers according to the information of the primary and secondary, and complete or control one task together. The system has a distributed operating system with an internal structure that is completely transparent to the user and manages system resources globally.

The application of Internet technology in enterprise personnel identification and management systems has had a huge impact on enterprises, so that most enterprises need to integrate computer network technology to access application systems through the Internet. Developers will build web servers within the enterprise to allow the application system to provide internet capabilities and use ASP technology to rewrite and distribute the corresponding system application logic to the server. The system organization is shown in Figure 1.1. 


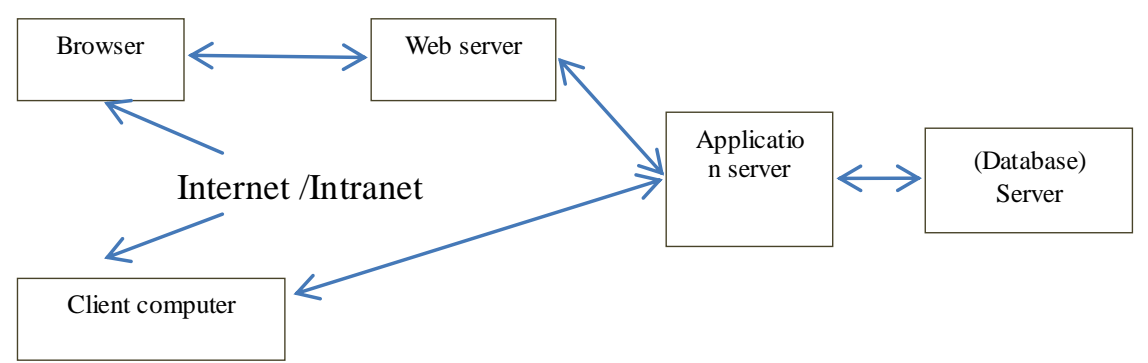

Appearance presentation layer Business logic Data service layer

Figure 1.1 Schematic Diagram of Distributed Multi-layer Application System

The general distributed computer network system management system mainly includes: OSI network management system with strong management scope and effect, and SNMP network management system capable of effectively managing TCP/IP. Each sub-computer network within a distributed computer system is independent of each other and does not require risk.

The Multi-tier Distributed Application Services Suite is a way to build a powerful database of multi-tier database heroes to build distributed database applications. The client connects to multiple client dataset controls using a database for data browsing and editing, and the IAppServer interface and the application server client DCOM establish communication by the application server remote data module. Figure 1.2 illustrates the MIDAS-based multi-tier application architecture.

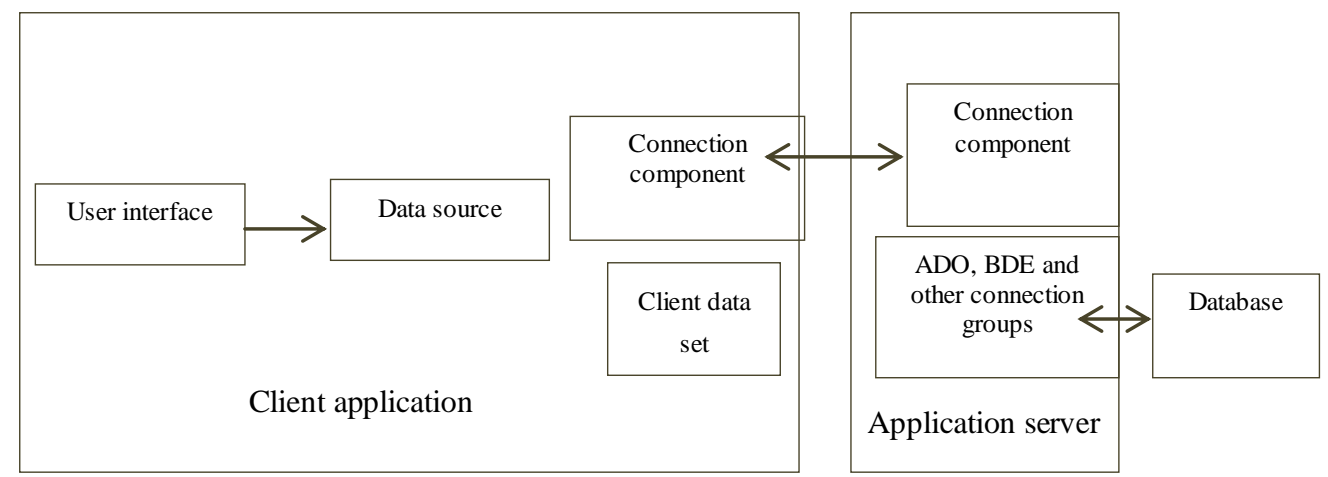

Figure 1.2 Multi-layer Application based on Distributed Computer Network Technology

The overall flow chart based on the personnel identification and management system reflects the operational flow of the system. The flow chart of this system is shown in Figure 1.4:

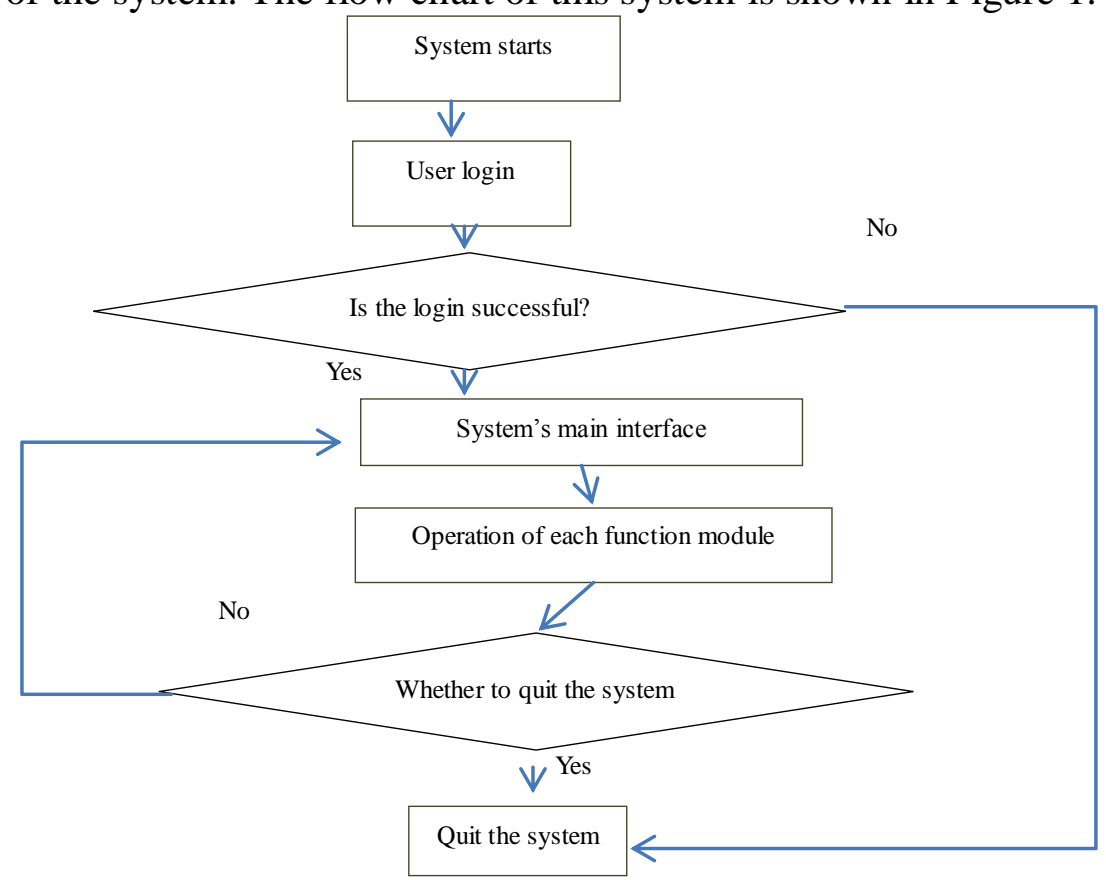

Figure 1.3 Personnel Identification and Management System Flow Chart 


\section{Analysis of Personnel Identification and Management System Based on Distributed Computer Network Technology}

The system analysis mainly analyzes whether the personnel identification and management system based on distributed computer network technology is feasible through requirements and feasibility. The requirements analysis understands the purpose and principles of the designer's identification and management system. It includes user requirements for functions, performance, and database.

Table 2.1 shows the functional requirements of the personnel identification and management system, including system management, job management, employee information management, salary and benefits management, and report generation.

Table 2.1 Main Functions of Personnel Identification and Management System based on Distributed Computer Network Technology

\begin{tabular}{|c|c|c|}
\hline Category & No. & Description \\
\hline \multirow{4}{*}{$\begin{array}{l}\text { System } \\
\text { management }\end{array}$} & h-01 & Password management, you can modify the login password \\
\hline & h-02 & User management, add new users and set user permissions \\
\hline & h-03 & Data backup and restore, back up and restore data \\
\hline & h-04 & Exit the system, exit the system after the operation is completed. \\
\hline \multirow{6}{*}{$\begin{array}{c}\text { Post } \\
\text { management }\end{array}$} & h-05 & Job description, describe a job information \\
\hline & h-06 & Department staff, including personnel \\
\hline & h-07 & Internal title, title of each member \\
\hline & h-08 & Departmental arrangements, which departments are included \\
\hline & h-09 & Job transfer, job transfer description \\
\hline & $\mathrm{h}-10$ & High resignation, departure of retired personnel \\
\hline \multirow{2}{*}{$\begin{array}{c}\text { Staff } \\
\text { information } \\
\text { management }\end{array}$} & h-11 & Basic employee information, basic information of employees \\
\hline & h-12 & Family member status, employee's family member information \\
\hline \multirow{4}{*}{$\begin{array}{c}\text { Salary and } \\
\text { benefits } \\
\text { management }\end{array}$} & h-13 & Employee salary \\
\hline & h-14 & Whether employees are insured \\
\hline & h-15 & Insurance payment, employee insurance payment description \\
\hline & h-16 & Performance appraisal, performance appraisal of employees \\
\hline \multirow{3}{*}{$\begin{array}{c}\text { Generate } \\
\text { report }\end{array}$} & h-17 & Daily report, user operation log and report \\
\hline & h-18 & $\begin{array}{c}\text { Performance appraisal report, employee performance appraisal } \\
\text { report }\end{array}$ \\
\hline & h-19 & Job transfer report, employees' position transfer report \\
\hline
\end{tabular}

In order to enable the long-term operation of the personnel identification and management system based on distributed computer network technology, the management system should have: security in identity authentication, access control, and database security; the presentation layer is relatively independent of the business logic layer and is easy to modify and upgrade with flexibility; the system can increase the scalability of new functions without affecting other modules; The ease of use of the operating system from the customer's perspective; from a user perspective, the system is easy to maintain and practical.

Technical guidelines for personnel identification and management systems based on distributed computer network technology: different roles have different permissions. The user only views the post information and the post administrator can query, add, delete, and modify different post information. Jobs, systems, employee information, and payroll benefits management; able to enter, export, modify, and delete information in the database; processes that can be categorized by job and have basic processing and data.

Personnel identification and management system based on distributed computer network technology does not require professional computer language experience for ordinary users. The operation interface should be simple and easy to operate. According to different positions, there is 
corresponding operation authority, and from the user's point of view, it has the operability of the examination, which means that the system is operationally feasible. Figure 2.2 shows the architecture of a web-based distributed system:

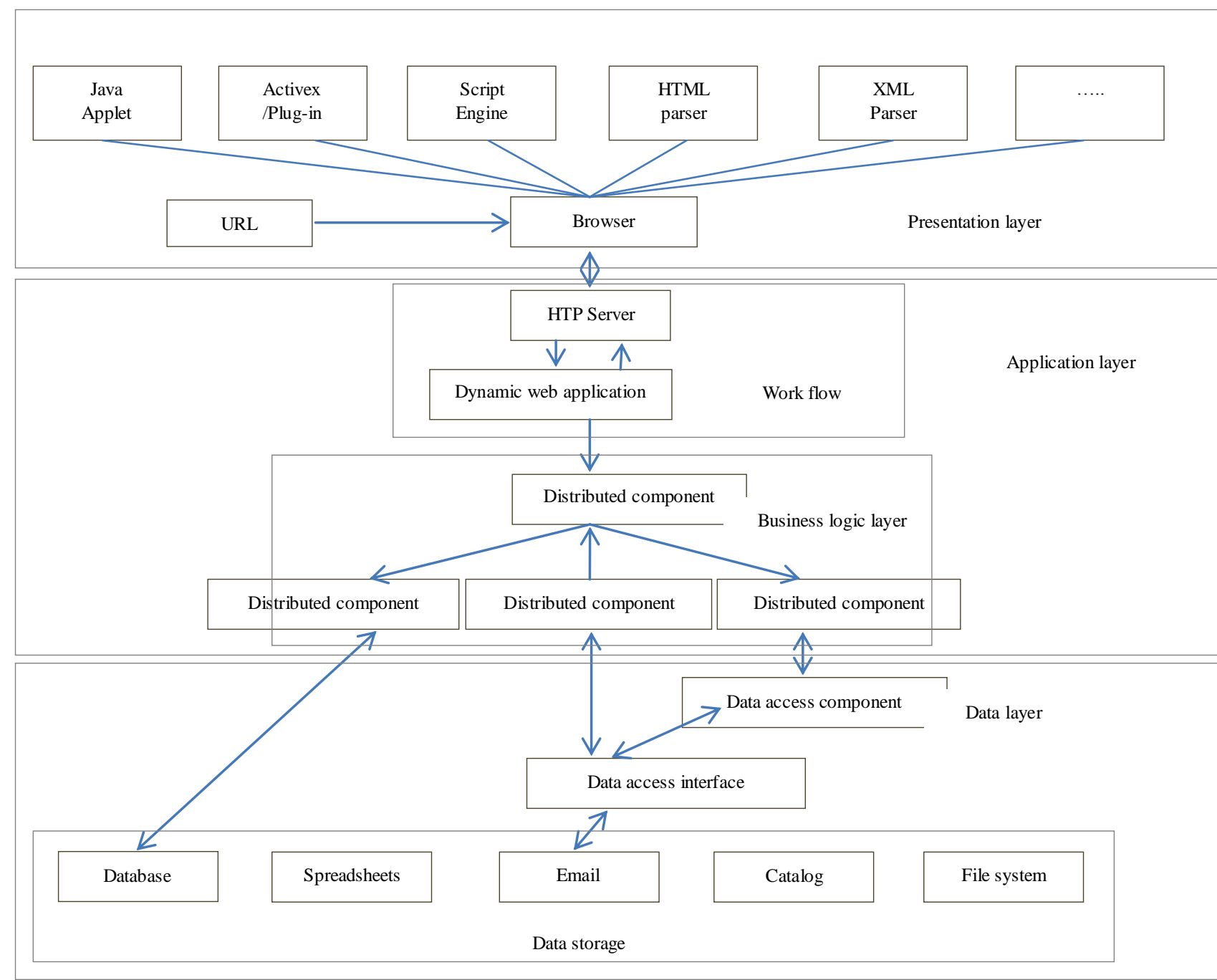

Figure 2.2 Architecture of Web-based Distributed System

The personnel identification and management system based on distributed computer technology needs to realize the database with various ways of linking, simple format, quick access, resource saving and application for Access, MySql and other applications. It contains a Connection to a specific database, a Command that can provide a request to the database, a parameter Parameter to the specified SQL query, an Error that can diagnose the error, a Recordest of the recordset obtained by the record query, a Property Property containing the static set, Corresponds to the data field Filed of the giant deer object and the Parameters that store the related Command possession objects, the Properties of the Connection and Command objects, the Errors that contain errors in the database operation, the Fileds that store the records corresponding to each field, and the Fileds of the Field object. In this regard, the structure of the personnel identification and management system for distributed computer network technology should have the problem of unified device management and reasonable balance of data information flow to provide better service for users.

The personnel identification and management system based on distributed computer network technology is an application system that uses database as a storage target and associates a series of components with functional modules for enterprise decision-making. Therefore, the architecture of the personnel identification and management system is shown in Figure 1.3: 


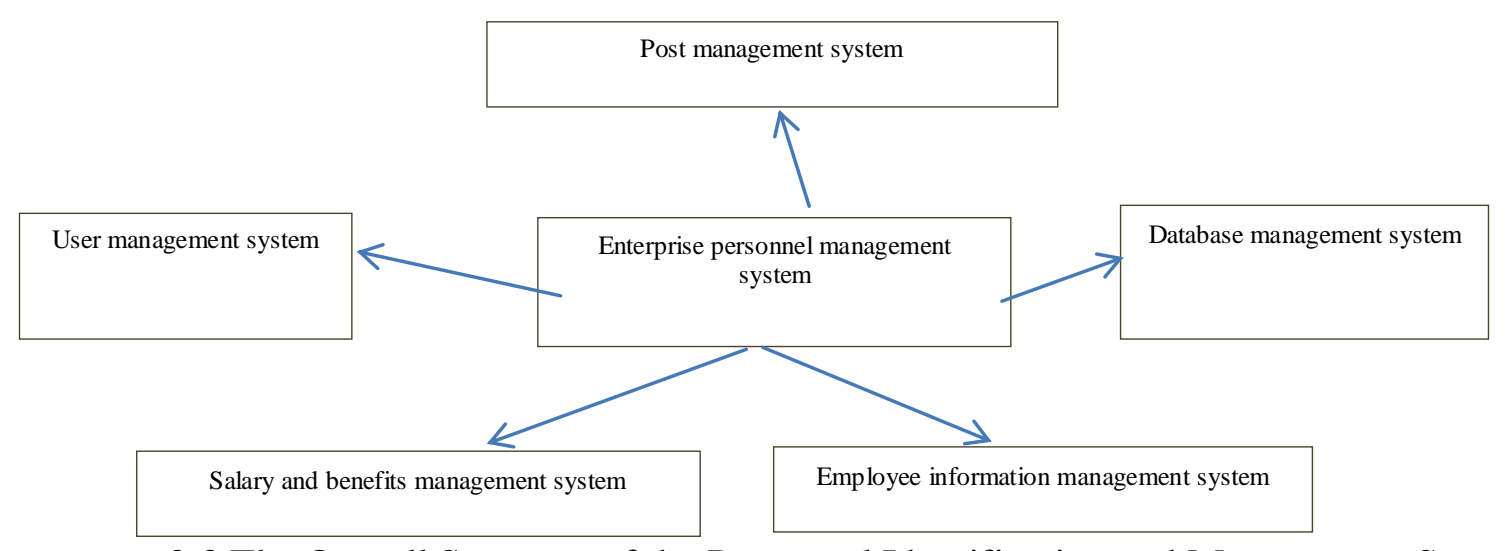

2.3 The Overall Structure of the Personnel Identification and Management System

The employee information module includes: obtaining an employee form (get Employee List), obtaining employee information (get Employee Information by Employee ID) based on the employee number, and finding an employee superior (get Superior of Employee ID). Its function is to find employee information through the employee label; his program logic is to accept user requests and information and find the accurate data in the database according to the required information in the return user number; His interface definition is: input parameter interface Input Param Interface: Get Superior of Employee ID Soap In and output parameter interface: Output Param Interface: Get Superior of Employee ID Soap Out; User data representation (XML schema).

The welfare modules include: update Application Form Status, approve Application Form Status, reject Application Form Status, submit Application Form Status, etc. Its function is to pass the employee's completed sentiment statement to the relevant department; his program logic is to accept the user request and information and check and put the matching user data into the database to return the submission success; the interface is defined as: Input Param Interface: submit Application Form Soap in and Output Param Interface: submit Application Form Soap Out; user data representation (XML schema).

The training modules include: create Application Form, update Application Form Status, approve Application Form Status, reject Application Form Status, submit Application Form Status, etc. Its function is to process the submitted application form by the administrator; its program logic is: accept user request and information and check to store the qualified data into the database and return "operational success". Its interface is defined as: Input Param Interface: approve Application Form Soap in and Output Param Interface: approve Application Form Soap Out; user data representation (XML schema).

The above is some distributed computer-based technologies used in the personnel identification and management system. The implementation of the main modules of the personnel identification and management system and some design processes are described.

\section{Conclusion}

Although the network environment is decentralized, this does not mean that a server can only manage one area. Distributed computer network technology is to divide a server into multiple sub-servers for multiple management and maintenance. Distributed computer technology with many advantages of its own structural performance is a fast-developing high-tech industry. It can meet the diversified and high-level needs of various users, and the emergence of this technology has greatly improved the efficiency of enterprise personnel identification and management systems and reduced costs, and better serve the decision-making level of enterprises. Personnel identification and management based on distributed computer technology frees managers from the traditional personnel management model, simplifies management processes, improves management levels, and promotes the rapid growth and development of enterprises and public institutions. Based on this, based on the establishment of distributed database, the classic relational database and XML are combined into the database to store the formatted data to process the data efficiently, which 
improves the versatility and efficiency of the personnel identification and management system. Therefore, the personnel identification and management system based on distributed computer network technology has great influence on enterprises.

\section{References}

[1] Luo Pingping. Thoughts on the Informationization and Network Construction of Enterprise Archives-Taking Shenzhen Mawan Power Plant as an Example[J]. Archives of Electromechanical Ships, 2009(03): 65-66.

[2] Liu Chengliang. Discussion on Constructing Campus Computer Network Security Protection System[J]. Information and Computer (Theoretical Edition), 2013,8:87-88.

[3] Su Yubei; Cao Yang; Huang Ping; Huang Tianxi; Application Research of Intelligent Technology in Distributed Network Fault Management [A]; Proceedings of China Intelligent Automation Conference 1999 (Volume 2) [C]; 2012

[4] Zhao Min, Wang Yuwang, Yan Xingchun. Research on Database Security of Human Resource Management System Based on C/S and B/S Mode[J]. Computer and Information Technology, 2005, (2).doi:10.3969/j.issn.1005-1228.2005.02.016.

[5] Jin Hanjun, Wang Linping, Liu Jianqing. Design and Implementation of Computer Course Selection System Based on Network Environment[J]. Journal of Huazhong Normal University (Natural Science), 1999(01

[6] Liu Xinyu, Luo Zhongqiong, Wang Yongjie. Research and Development of Graduate Education Management Information System[J]. Journal of Southwest Jiaotong University (Social Science Edition), 2002(03): 87-90

[7] Lin Yong, Ni Youyuan. Development and Research of Graduate Degree Management Information System[J]. Journal of Anhui University of Science and Technology (Social Science Edition), 2008(04): 80-84.

[8] Chen Yueying, Zhuang Weihua, Hu Xiaojun. Conflicts and Research in the Development of Course Selection System Based on Network Environment[J]. Microcomputer \& Application, 1998(12):57-58. 